\title{
DYE TRACING THROUGH THE VADOSE ZONE ABOVE WIND CAVE, CUSTER COUNTY, SOUTH DAKOTA
}

\author{
James Nepstad \\ Effigy Mounds National Monument, 151 HWY 76, Harpers Ferry,Iowa, USA, jim_nepstad@nps.gov
}

\begin{abstract}
During the 1990s, in an attempt to better understand threats posed by surface developments overlying the cave, National Park Service staff at Wind Cave National Park in Custer County, South Dakota carried out a series of dye traces through portions of the vadose zone overlying the cave. Wind Cave is located within the 100 $\mathrm{m}$-thick Madison formation (limestone and dolomite), which in most locations is capped by varying thicknesses of the basal units of the Minnelusa formation (intermingled beds of sandstone, limestone, and shale). A variety of cave locations with dripping or pooled water were monitored for up to five years following dye injection. Transit times to the cave varied from less than six hours to as much as 4.8 years. Despite a variety of positive results, there appears to be little correlation between transit time and lateral or vertical distance from the injection site. Data analysis produced traditional-shaped dye recovery curves in some locations, albeit stretched out over hundreds and possibly even thousands of days beyond dye injection. The results strongly suggest that chemical or sewage spills in the vicinity of the dye injection sites would quickly enter multiple sites in the cave system, and could persist for years.
\end{abstract}

\section{Introduction}

Wind Cave is located within Wind Cave National Park in the southern Black Hills in Custer County, South Dakota. The cave is an extensive three-dimensional labyrinth that as of this writing consists of more than $230 \mathrm{ki}-$ lometers of surveyed passages contained within an area of roughly 2.5 square kilometers (Ohms, 2015, personal communication). It is contained within the Madison formation, which consists of beds of limestone and dolomite of Mississippian age roughly 100 meters in thickness in the Wind Cave area (Palmer and Palmer, 2008).

Overlying the Madison formation in the vicinity of the cave is the Minnelusa formation, consisting of sandstone, limestone, dolomite, and shale (Strobel and others, 1999). The vast majority of Wind Cave is capped by the lower 30 to 100 meters of the Minnelusa formation, but a small number of cave passages are located beneath areas where the overlying Minnelusa formation has been largely or entirely eroded away. The only known completely-natural entrance to the cave is located in such an area, in a drainage known as Wind Cave Canyon (Figure $1)$.

The contact between the Minnelusa and Madison formations is complex. The Madison was exposed soon after deposition, and a karst topography formed, with many caves, sinkholes, and other typical karst features. As a result, the base of the Minnelusa was deposited atop an irregular surface, and in the process it filled many former solutional features up to tens of meters below the highest remaining reaches of the Madison (Palmer and Palmer, 2008).

The area above Wind Cave is semi-arid with a meanannual precipitation of $45.8 \mathrm{~cm} /$ year (Ohms, 2012). Streambeds above the cave area have highly intermittent flow, and there are few locations within them that would appear to capture what flow they occasionally have in any obvious way.

Wind Cave National Park was established in 1903, making it one of the oldest national parks in the United States. For the convenience of the visiting public, the park headquarters and its associated buildings, utilities, and parking lot were established near the cave's en-

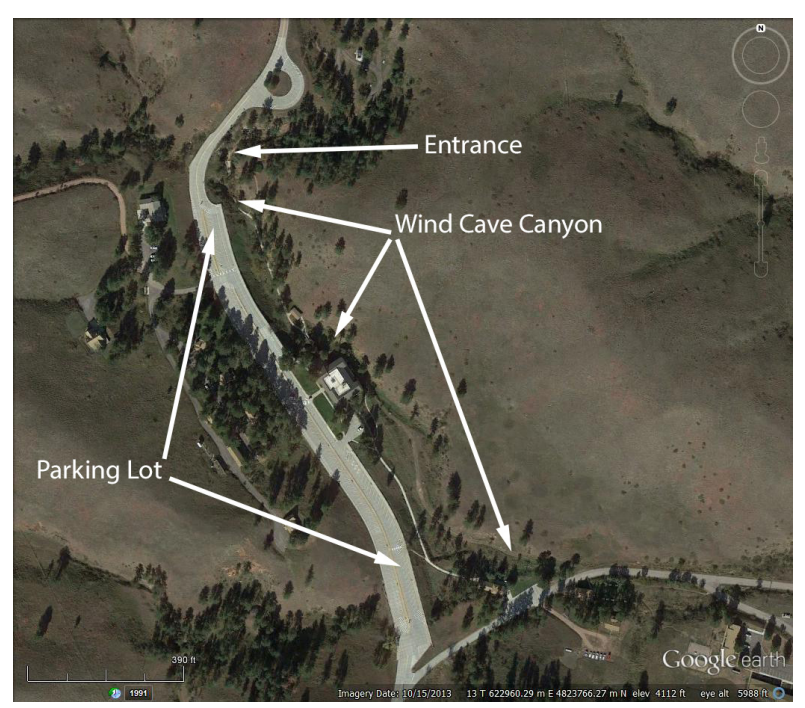

Figure 1. An aerial image of surface features and developments located in the vicinity of the entrance to Wind Cave. 
trance. During the 1980's and 1990's, park staff became increasingly concerned about the aging infrastructure lying above the cave. Water and sewer lines were known to be compromised, and untreated runoff from the 1-hectare asphalt (at that time) parking lot was entirely disappearing within 15 meters of the drains, which are located in Wind Cave Canyon (Nepstad, 1997). How much of the cave was affected by these potential contaminant sources? How long did it take to reach the cave? Once there, how long was the contamination present?

To answer these questions, it was necessary to trace water from the surface to the cave. Although dye tracing with fluorescent dyes has been commonly employed for this purpose for decades, the circumstances at Wind Cave presented challenges. The surface overlying the cave lacks traditional karst features such as sinking streams or sinkholes, requiring ingenuity with respect to the selection of dye injection sites and dye injection methods. Rather than injecting dye into a sinking stream and testing for it at resurgences or within cave streams, it would be necessary to trace diffuse flow through the vadose zone directly above the cave.

\section{Previous Work}

In 1986, Marsha Davis, a graduate student at the University of Minnesota working under E. Calvin Alexander, conducted two dye traces at Wind Cave (Alexander and others, 1989). The objective of the traces was to determine whether links existed between the park's visitor center parking lot and wet areas in the underlying cave. On July 19, 1986, 1122 grams of fluorescein (Acid Yellow 73) was injected into a small swallow in the middle of Wind Cave Canyon in the park's picnic ground, along with roughly 1,000 liters of water. On August 16, 1986, 1076 grams of rhodamine WT (Acid Red 388, often referred to generically as rhodamine throughout this paper) was injected with several thousand liters of water beneath the south parking lot drain - located near the elevator building.

At the time of these traces, there was no database documenting the location of wet areas within Wind Cave. Park staff and volunteer cavers, acting on personal recollections, were able to inform Davis of a limited number of sites in the vicinity of the injection points with known dripping or pooled water. Frustrated at not being able to provide researchers with more information for such a critical study, in 1989 park staff instituted an aggressive inventory of cave features at Wind Cave. By the early 1990 's, inventory data was already showing that Davis' work had missed several key wet areas.
Despite the fact that sampling was unintentionally incomplete, Davis reported some positive results for both traces. Fluorescein was reported at survey stations NFP5 (Fairy Palace) and NM4 (Before Fairy Palace). Possible fluorescein was reported at RS11 (Minnehaha Falls). Following some background sampling in these areas in 1993-1995, park staff learned that Fairy Palace and Before Fairy Palace consistently produce false positives for fluorescein. Minnehaha Falls still had small traces of fluorescein present at that time, but due to its location beneath the south parking lot drain, park staff suspected that the fluorescein present there was from antifreeze spills on the parking lot. All of this, combined with the scarcity of sampling sites and the short duration of sampling (only about three weeks), created some skepticism regarding the reported fluorescein results.

Davis' rhodamine WT trace also produced some positive results. One site, RS11 (Minnehaha Falls), produced dye within two days of injection. A few other sites also eventually tested positive for dye including RS13 (Mule's Ears), UB10 (Caving Tour Drips), and C58 (Garden of Eden Drips). Dye may have shown up at additional sites, but once again monitoring was limited to a small number of sites in the cave and was cut off relatively early.

A year following the injection of the rhodamine, dye began showing up in the park's well, located within Wind Cave Canyon about $2.7 \mathrm{~km}$ east of the rhodamine injection site off the parking lot. Davis attributed the dye in the well to a rhodamine WT injection two months earlier into the Beaver Creek sink, located about $3.8 \mathrm{~km}$ northwest of the well, but since the same dye had been used for both traces, an additional trace would be necessary to produce conclusive results.

By 1992, the number of cave management staff at Wind Cave National Park had grown sufficiently that it was possible to contemplate additional dye traces. Park staff, advised by Joe Meiman, a hydrologist who worked for Mammoth Cave National Park at the time, began to experiment with alternative methods of tracing water through the overlying vadose zone. The persistence of Davis' dyes in the vicinity of her traces led them to experiment with Lycopodium spores. Given the limited number of fluorescent dyes available, it was hoped that if such a trace could be successfully accomplished, a nearly unlimited number of tracing elements would be available, since the spores could, in theory, be dyed with a large number of colors. 
An experimental trace was attempted in 1992, when roughly 200 grams of Lycopodium spores, together with approximately 200 gallons of water, were injected in the same small swallow that Davis had injected her fluorescein into back in 1986. Sampling stations containing 10 micron filter paper were placed beneath several cave drips that were known to respond quickly to rain events on the surface, including some that Davis had believed tested positively for dye during the 1986 trace. The filters were removed from the cave on an occasional basis and examined carefully with a microscope. No spores were ever detected, so the Lycopodium experiment was largely a failure, probably due to the filtering effect of overlying soil and sediments in the epikarst.

By coincidence, however, park staff had been background testing the water at many of these same sites for the presence of optical brightener, in the hopes of using that dye as a tracer element in the future. Untreated cotton had been left in several of these locations, and these samples were observed under a handheld UV lamp after being removed from the cave. During the Lycopodium experiment, a cotton sample from NM4 (Before Fairy Palace) was found to be strongly positive for optical brightener. Park staff were puzzled by this occurrence, since all known potential sources of optical brightener (leaking sewage lines) were located down-dip from this location. Eventually it was recalled that the Lycopodium spores had been prepared for injection by mixing them with four liters of water mixed with laundry detergent (to prevent clumping). Although the Lycopodium experiment proved to be a failure, it is interesting that it indirectly led to a successful dye trace of sorts.

By 1993, it appeared as though future traces would have to resort to utilizing the limited number of fluorescent tracer elements available at that time. A series of three traces were planned for that year utilizing fluorescein, rhodamine WT, and optical brightener. All of the traces were conducted considerably to the west of the 1986 traces. Over 60 sampling locations were set up, blanketing nearly all of the known portions of the cave. Small samples of untreated cotton and activated charcoal "bugs," consisted of a few grams of activated charcoal contained within a small screen pouch, were tested on at least a quarterly basis for a full year prior to dye injection in order to gather background data.

Once they were removed from the cave, the charcoal bugs were eluted with roughly $10 \mathrm{cc}$ of an elutant consisting of 1-propanol, de-ionized water, and ammonium hydroxide (mixed at 5:3:2), then tested with a Turner Model 111 fluorometer with the filters appropriate for the spectra of the dyes to be used. Cotton samples were visually examined for optical brightener exposure with a handheld UV lamp.

With the exception of the single cotton sample that tested positive for optical brightener described in the Lycopodium experiment and a few weak positives for fluorescein or rhodamine in the vicinity of the 1986 work, the entire cave proved to be free of the presence of all three dyes.

On June 14, 1993, 1000 grams of a 20\% rhodamine WT solution was injected into the bottom of a small sink in a drainage roughly overlying the Club Room portion of the cave, along with roughly 350 liters of water from a pumper truck. The water in the truck had been left exposed to the atmosphere for four days to allow any residual chlorine from the park's water treatment system to dissipate. Roughly 125 liters went in prior to the dye, with the remaining 225 liters going in after the dye had been poured into the sink.

On July 6, 1993, 1008 grams of fluorescein powder mixed with 10 liters of water was injected into a small depression above the southeast portion of the cave, along with roughly 1200 liters of chlorine-free water from a pumper truck. About a third of that water was injected prior to the dye, while the remainder was used to flush it into the system. Later that same day, 4000 grams of Tinopal CBS-X (Fluorescent Brightener 351), an optical brightener, was injected along with roughly 25000 liters of chlorine-free water into a small depression in a drainage overlying the southwestern portion of the cave.

During the 1986 traces in Wind Cave Canyon, dyes were injected either directly into the cave-bearing Madison formation, or into the lowest five to ten meters of the overlying Minnelusa formation. The dyes used in the 1993 traces were injected considerably further up into the Minnelusa "cap" above the cave. The rhodamine trace above the Club Room was roughly 25 meters further up in the Minnelusa, while the fluorescein and tinopal traces were injected 50-65 meters up into it.

No longer dependent on visiting researchers for sampling, these traces were sampled by park staff according to a far more rigorous schedule, and for a much longer period of time. Some sites were monitored on a daily or weekly basis for months, and the remainder of the sites were monitored at least quarterly. After two full years of monitoring and over a thousand samples being collected, no dyes were detected in the cave from any of the 1993 injections. 
While the 1993 traces appeared to be failures at first glance, they nonetheless demonstrated a critically important principle. Unlike dyes injected at the very base of the overlying Minnelusa formation, which could arrive in the cave in a matter of days, dyes injected further up into the Minnelusa were either carried away laterally from the cave area, or diffused or delayed by the Minnelusa cap to such an extent as to render them undetectable for at least two years.

The 1993 traces taught park staff that the majority of its developments - its parking lots, buildings, and sewer and water lines - were perched above the most hydrologically vulnerable portion of the cave, where the protective Minnelusa formation was thinnest. It was time to supplement the results of the 1986 traces to get a better idea of the extent of this problem.

\section{The 1996 Traces}

In early 1996, additional background sampling demonstrated that dye from the 1986 traces was either entirely absent or barely detectable at cave sites.

Utilizing the park's extensive cave inventory database, park staff were able to identify over 60 locations suitable for sampling in areas including and surrounding Davis' earlier sampling locations. Following a final round of background sampling in the spring of 1996 (including both grab samples and bugs), plans were made to once again inject the same dyes into the same locations utilized in 1986 (see Figure 2) in an attempt to better quantify the extent of the cave influenced by these surface locations, and to better measure travel times and dye persistence.

On July 29, 1996, 2142 grams (1800 ml) of a 20\% rhodamine WT solution, representing 428 grams of pure dye, was injected beneath the south parking lot drain, along with enough water to simulate a one-inch rain event roughly 140000 liters for this particular drain. About a third of that water was injected prior to the dye, while the remainder was used to flush it into the system. Unfortunately, due to the large quantity of water needed to accomplish this, there was no way to ensure the water was completely chlorine-free. Chlorine levels in the water were very low, however, as chlorination had been shut down for over 24 hours prior to opening the hydrant used to supply the water. As chlorine levels in the water are ordinarily very low to begin with, it likely destroyed very little of the dye.

Later that same day, 2339 grams of fluorescein powder mixed with about 20 liters of water was injected into the same small swallow near the park picnic ground that was used in 1986. As in the earlier experiment, roughly 1,000 liters of chlorine-free water from a pumper truck was used to inject the dye - about 350 liters before injection, and about 650 liters following it.

As in the 1993 traces, samples were collected in $40 \mathrm{ml}$ glass vials that were specifically labeled for each site. Due to a limited budget and the very large number of samples taken over the course of these traces, vials were reused. To avoid contamination once a site tested positive for dye, vials were rinsed with de-ionized water at least three times between uses, and droppers used to fill vials in the cave (emptied and rinsed prior to each use) were kept at each sampling site to avoid cross-contamination. Activated charcoal bugs were placed at each site as a means of confirming very weak positives, or detecting dye arriving at quantities too low to measure in grab samples.

Water samples from the first 444 days were analyzed with a Turner Model 111 fluorometer, and subsequent samples were analyzed with a newly-acquired Turner TD-700. For three weeks, both fluorometers were used to analyze samples to ensure consistency of results between instruments.

\section{The Rhodamine WT Trace}

It had been known for years that a site in the cave near survey station BI25 (Upper Minnehaha Falls), located almost directly below the parking lot drain, consistently

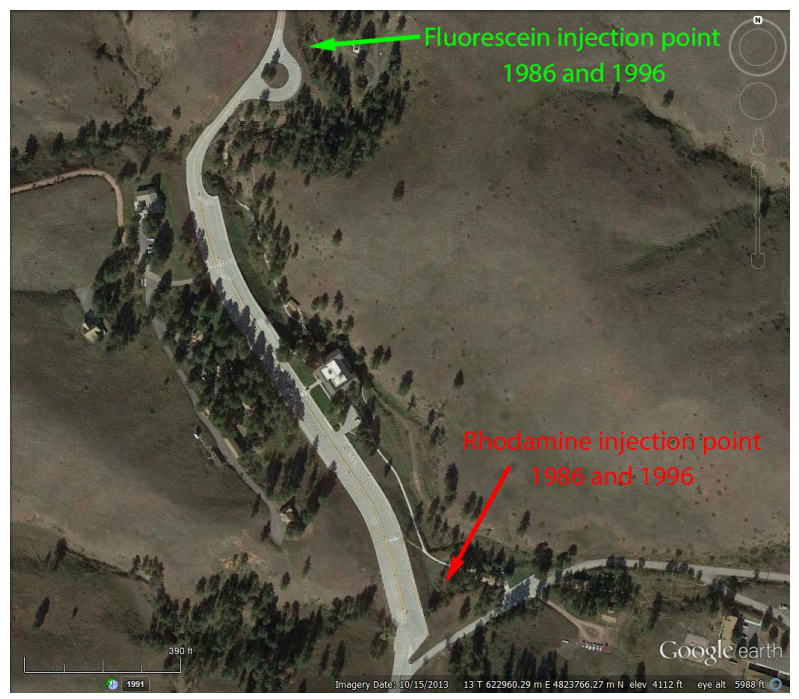

Figure 2. The locations of the 1986 and 1996 dye injection points on the surface above Wind Cave. The same dyes were injected in the same locations utilizing the same methods for both traces. 
responded to rain events within a matter hours. It was believed that the dye would make its initial appearance in the cave here, so an auto-sampling device was installed to automatically collect samples on an hourly basis following the rhodamine injection. Unfortunately it missed the first five hours following injection.

The first sample collected at BI25 was more than double the barely detectable pre-injection background level of 0.07 parts per billion (ppb), and one hour later it was nearing $1 \mathrm{ppb}$. By midnight that evening, it was approaching $20 \mathrm{ppb}$. Already a site had been discovered that received dye several times faster than the site that first went positive in 1986 (RS11, Minnehaha Falls).

BI25 would go on to become the most carefully documented site during the life of this dye trace. The site is easy to access, and was sampled on an hourly basis for weeks, on a nearly-daily basis for over a year, and several times per week following the first year, until the author left the park in October 1998. The rhodamine results from this site are very interesting. The first two years are illustrated in Figure 3.

A plastic tarp was arranged beneath the site to capture most of the flow to allow for the measurement of flow rates, which proved to be highly variable. Following heavy rains during the spring and summer, steadily streaming or heavily dripping water will pour in from a dome above the site at up to $1700 \mathrm{ml}$ per minute. Flow rates quickly reach a peak within a day of the rain event, and just as quickly fall off in the days immediately following. The steep peaks in the drip rate in Figure 3 all relate to heavy rain or melting events on the surface. During cold, dry stretches in the winter, the drip rate slows dramatically, and on some occasions even ceases completely.

Rhodamine levels rose steadily at the site for a week, rising to $87 \mathrm{ppb}$ before declining to $43 \mathrm{ppb} 11$ days after injection. It appeared as though the peak dye concentration had come and gone, and the site would continue to rapidly decline over the coming weeks. On the twelfth day after the rhodamine was injected, the first significant rain event on the surface occurred. As expected, drip rates quickly rose, but dye levels surged even faster, peaking at $250 \mathrm{ppb}$ two days later before starting yet another decline. Another rain event occurred on the seventeenth day, creating another rapid surge in dye levels that peaked at $380 \mathrm{ppb}$ within 48 hours. This reading on the nineteenth day proved to be the true peak at this site. Although spikes in dye concentration continued to occur

\section{Rhodamine WT Concentrations - Upper Minnehaha Falls (BI25)}

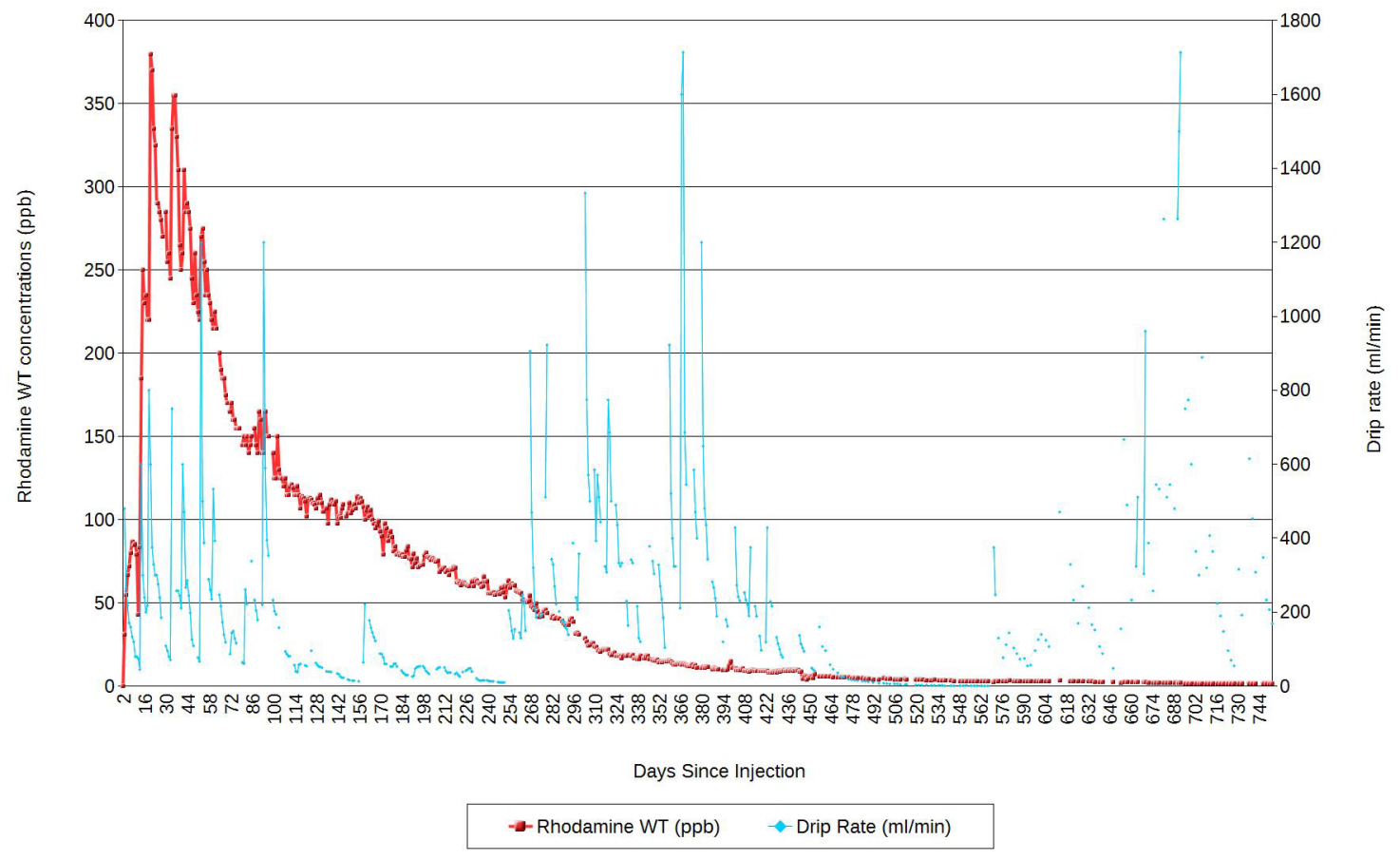

Figure 3. The results of the first two years of sampling at BI25 (Upper Minnehaha Falls). This was the most carefully studied site in the 1996 traces. 
immediately following subsequent precipitation or melting events on the surface, the magnitude of the spikes gradually decreased in the months following injection. They become barely noticeable after about 300 days. Despite the spikes which occurred early in the trace, the overall shape of the concentration curve strongly resembles a traditional "positively skewed, bell-shaped curve that is steeper on the rising limb than on the falling limb," (Mull, et al, 1988), except that instead of a time scale measured in hours or days, the time scale here stretches over multiple years.

The persistence of the dye in the system was rather remarkable. Nearly 1200 days following the injection, dye concentrations were still double the background levels measured prior to the 1996 dye injection. This persistence perfectly illustrates the threat posed by having the parking lot perched above the cave in this area. If contaminants in parking lot runoff behave like the rhodamine used in this trace, then relatively minor spills on the parking lot could impact cave resources for years following an incident.

BI25 was an interesting site, and it received more attention than any other sampling location during the 1996 rhodamine trace. But it was by no means the only site in the cave where positive results were found. Table 1 documents all of the sites that received measurable quantities of rhodamine, together with the number of days it took for the leading edge of the dye to reach those sites and the number of days it took dye concentrations to reach their peak.

There appears to be no clear correlation between the emergence of dye at a site, its peak concentration, or the time it took to peak and any of the other variables associated with a site. Some sites at a greater horizontal distance away from the injection point went positive well before other sites that were nearly beneath it. Likewise, vertical depth is a poor indicator of when dye will arrive or at what concentration it will peak, as is the drip rate associated with a site. Rather, travel times and peak concentrations appear to depend on highly local but unmeasurable variables, such as the site's proximity to hidden flow networks in the epikarst, the presence or absence of clay-bearing paleofill deposits in the overlying strata (which could prevent or slow more direct flow to the site), or the mixing characteristics of other waters encountered in transit.

The concentration curves for many of these other sites also resemble the classic shape of curves associated with traditional dye traces in karst aquifers. Other sites exhibit concentration curves that are anything but tra- ditional. See Figure 4 for examples of both. Concentrations at C47 (Assembly Room), for instance, rise abruptly once dye arrives, but remain relatively flat over the course of an entire year before increasing once again. One cannot even be certain the peak concentration had been measured after nearly 1000 days, when sampling finally ceased. Likewise, we cannot be certain that the peak concentration was measured at either C53 (Escape Route) or C53A (Silent Lake) after more than two years of sampling. Years of additional sampling may have been necessary in order to capture an entire curve at these sites.

\section{Rhodamine Recovery}

Accounting for the dye introduced in a vadose zone dye trace is challenging. In a traditional dye trace in a karst

\begin{tabular}{|l|r|r|r|r|r|}
\hline Site & \multicolumn{1}{|c|}{$\begin{array}{c}\text { Depth } \\
(\mathrm{m})\end{array}$} & $\begin{array}{c}\text { Horiz } \\
(\mathrm{m})\end{array}$ & $\begin{array}{c}\text { Days } \\
\text { to } \\
\text { Cave }\end{array}$ & $\begin{array}{c}\text { Peak } \\
(\mathrm{ppb})\end{array}$ & $\begin{array}{c}\text { Days to } \\
\text { Peak }\end{array}$ \\
\hline BI25 & 31 & 12 & 1 & 380 & 19 \\
\hline RS11 & 34 & 28 & 2 & 235 & 35 \\
\hline BI9 & 56 & 15 & 2 & 290 & 19 \\
\hline RS13 & 31 & 31 & 17 & 9 & 56 \\
\hline SA1 & 40 & 87 & 23 & 23 & 93 \\
\hline SA1A & 42 & 85 & 23 & 11 & 57 \\
\hline UB10 & 57 & 54 & 44 & 6 & 160 \\
\hline RS10 & 34 & 28 & 83 & 3.5 & \\
\hline BI12 & 46 & 21 & 99 & 4.5 & \\
\hline C53A & 34 & 40 & 114 & 0.96 & 697 \\
\hline UU10 & 47 & 8 & 155 & 1.5 & 245 \\
\hline SK3 & 36 & 49 & 232 & 8.5 & 380 \\
\hline SK3F & 38 & 43 & 232 & 2.6 & 629 \\
\hline C53 & 37 & 40 & 233 & 3.39 & 725 \\
\hline SK6 & 41 & 62 & 246 & 0.25 & 413 \\
\hline C47 & 57 & 33 & 414 & 0.41 & 957 \\
\hline UYA4 & 48 & 111 & 414 & 0.12 & \\
\hline
\end{tabular}

Table 1. Cave sites that tested positively for rhodamine WT following the July 1996 injection. Also listed are the vertical and horizontal distances from the injection point, days following injection that dye was first detected, the peak concentration measured, and the number of days following injection that the peak concentration occurred. Missing data for RS10, B112, and UYA4 are due to very infrequent sampling at those sites. 


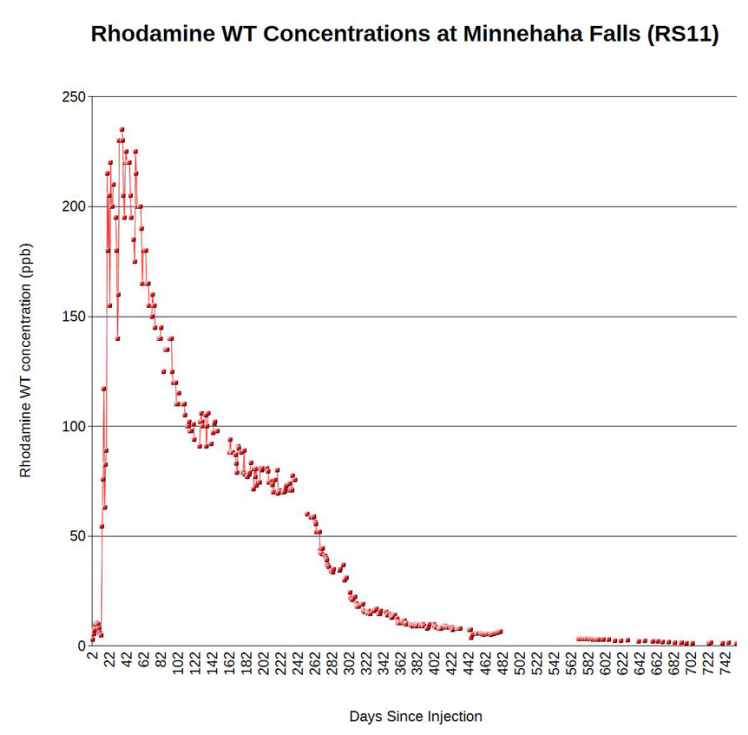

Rhodamine WT Concentrations at C47 (Assembly Room)

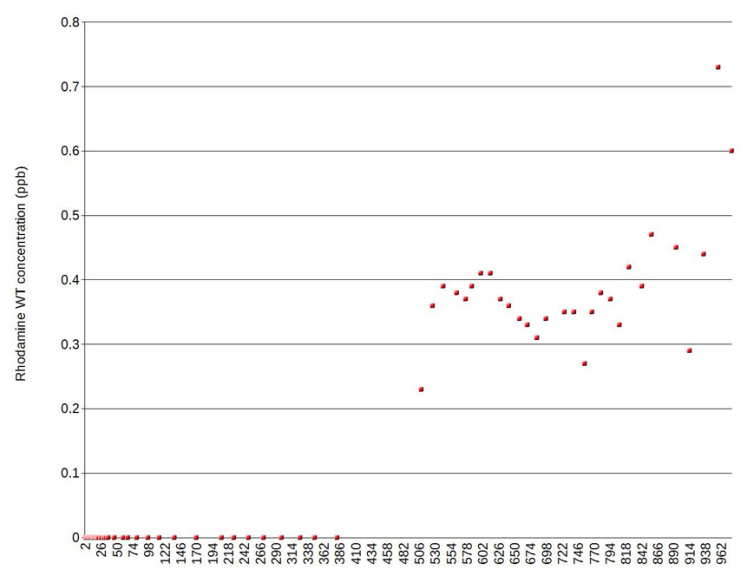

Days Since Injection

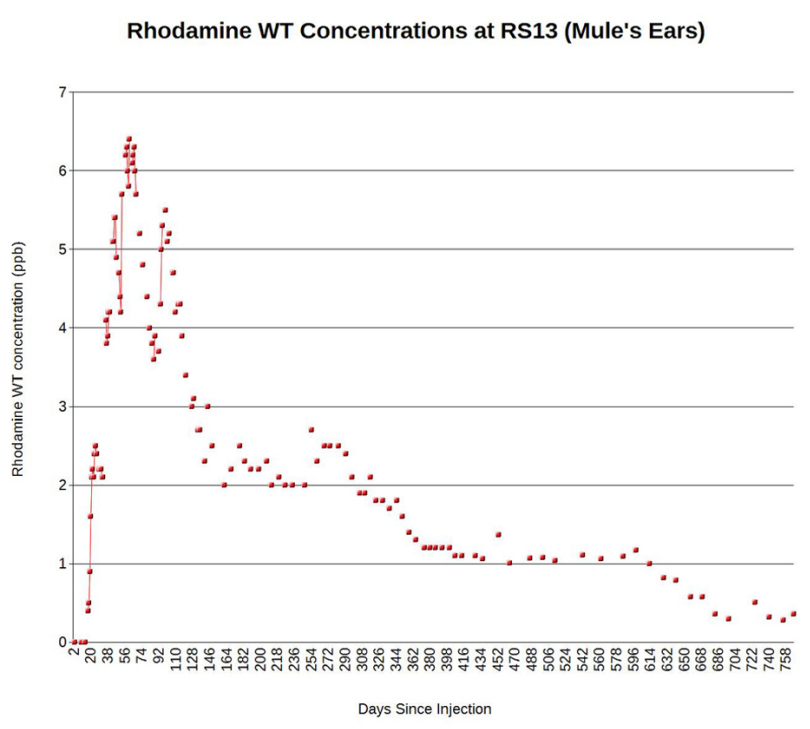

Rhodamine WT Concentrations at C53A (Silent Lake)

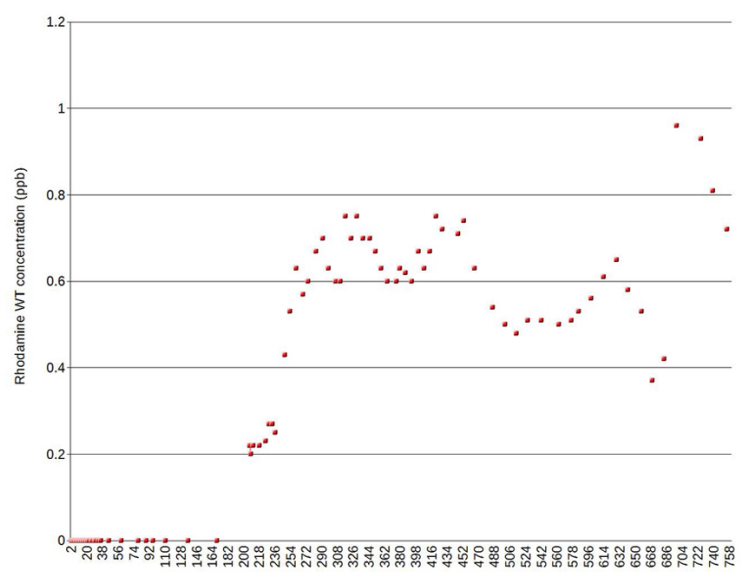

Days Since Injection

Figure 4. Sampling sites such as RS 11 and RS 13 had traditional-shaped dye curves, albeit stretched out over periods of hundreds of days. Other sites, such as C47 and C53A had more complex curves, and may not have peaked before sampling concluded.

landscape, where dye is poured into a stream at an insurgence, the researcher can at least be relatively certain that a large proportion of the dye injected got into the system. Although park staff could be certain about the amount of dye poured onto the ground in these Wind Cave dye traces, it is impossible to know how much of that dye might have been adsorbed by soils and sediments at or near the injection point. Water and dye pooled over an area of roughly 150-200 square meters before gradually sinking, so the injection was not perfectly discrete. Although this was deemed acceptable, since the experiment was designed to model the fate of parking lot runoff and that was how parking lot runoff in the area behaved, it nonetheless introduces some complexity that is difficult to completely resolve. We can calculate roughly how much dye reached the various sites in the cave, but the fate of the dye beyond the sum total of all sites will remain a subject of speculation.

The vast majority of the dye that we can account for traveled through BI25. This site experienced not only the highest concentrations, but the highest flow rates as well. Over the course of the first two years following injection, flow rates averaged $227 \mathrm{ml} / \mathrm{min}$ at the site, and at times exceeded $1700 \mathrm{ml} / \mathrm{min}$. Other sites had far lower concentrations, or far lower flow rates, or both.

To arrive at an estimate for the quantity of dye captured at BI25, certain assumptions had to be made. It was assumed that each day's observed flow rate could be 
viewed as the mean flow rate for that day, and that each sample's dye concentration could be viewed as the mean concentration for that day. Likewise, if more than a day passed between samples, then the values for the most recent sample were used for the day(s) not sampled. While this inevitably resulted in over-calculating the daily mass flux on days when concentrations and/or flow rates were declining, the opposite surely happened on numerous occasions as well. It is assumed that the errors thus introduced into the estimate will cancel each other out, since the number of samples collected was quite large. Data was collected on 538 of the first 752 days, including 344 days during the critical first year following injection.

If this assumption is correct, then roughly 12.06 grams of rhodamine WT (dye, not dye solution) traveled through BI25 during the course of the first 752 days. Figure 5 illustrates the temporal distribution of the dye recovery, with the solid red line representing the running total of rhodamine received at the site by a given day. Roughly 9.1 grams arrived during the first summer and fall fol- lowing injection. The graph flattens significantly during the course of the winter of 1996-1997, as flow rates at the site markedly slowed. The total stood at about 9.9 grams at the beginning of the spring of 1997, and rose to 11.9 grams by the beginning of the winter of 1997-1998. During the spring, summer, and early fall of 1998, the total slowly rose to 12.06 grams. Although dye was still arriving at low concentrations at that time, extrapolating on this curve, it is difficult to imagine the total ever rising above 12.5 grams.

The sampling site at BI9 is beneath and just down-dip from BI25. Due to its location, and due to the fact that it tracked so closely with data from BI25 (they peaked at precisely the same time), it is strongly suspected that the water emerging at BI9 is water that has already flowed through BI25. Although it peaked at a lower concentration, this could be due to mixing that occurs after the water leaves BI25. Unless future evidence indicates otherwise, it is probably not appropriate to consider this site when accounting for dye recovery.

\section{Running Totals for Dye Recovered at BI25}

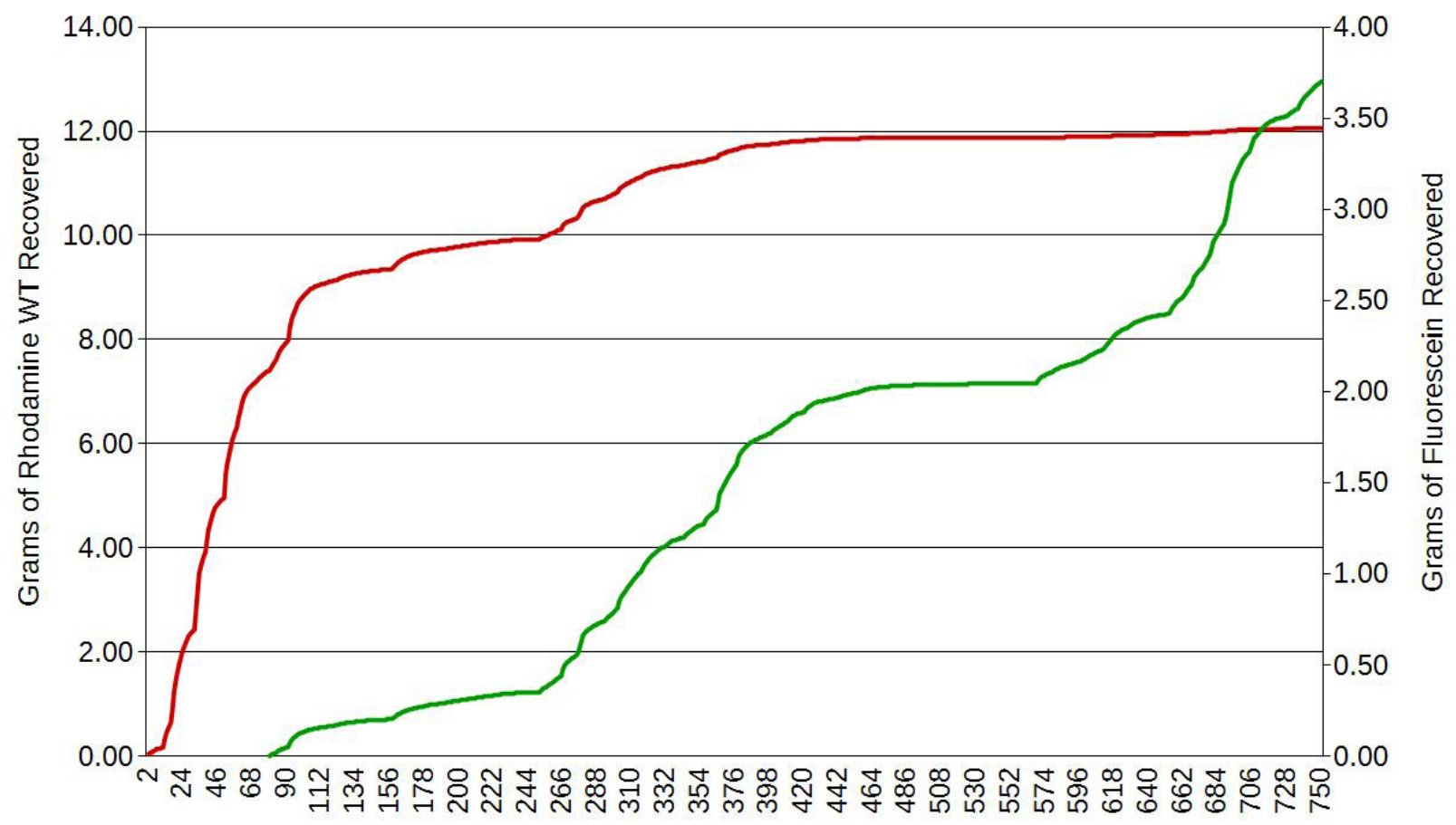

Days Since Injection

- Rhodamine WT Recovered - Fluorescein Recovered

Figure 5. Cumulative totals for dyes recovered at BI25 by a certain period in time. Note the rhodamine WT curve flattening significantly after the first year, compared to the fluorescein curve, which does not. Graph represents total dye recovered, not total dye mixture recovered. 
Another site where very high concentrations of dye were encountered was RS11, Minnehaha Falls. Although this site peaked at $235 \mathrm{ppb}$ about a month after injection, the flow rates here are much slower than those encountered at BI25 or BI9. Average measured flow was $4.9 \mathrm{ml} / \mathrm{min}$ ute at RS11, compared to an average $226.9 \mathrm{ml} / \mathrm{min}$ at BI25. Site conditions at RS11 prevented all flow entering the site to be measured, however. It is estimated that the total amount of water entering the site at any time is roughly double the measured flow.

A total of 309 samples from RS11 were collected and analyzed during the first 760 days following injection. As with BI25, if we assume that daily observed flow rates and dye concentrations are the mean values for that particular day, then a total of 0.18 grams of rhodamine passed through RS11 during the first 760 days of this trace. If our assumption is correct that twice as much water enters the site as a whole, and if that additional water had the same concentration as the water that was analyzed (which is likely, due to its proximity), then it is possible that a total of up to 0.36 grams of rhodamine WT entered the cave at RS11 during this time period.

The remaining sites were sampled far less frequently, and had significantly lower dye concentrations. Due to large gaps between sample collections, the author believes that recovery estimates are not precise enough to cite, but even considering simple order of magnitude basis estimates, most of these sites can account for a few hundredths of a gram total at best, with the possible exception of SA1, which may be able to account for a few tenths of a gram.

In all, it is fairly safe to say that less than 13 grams of dye can be accounted for from the rhodamine WT trace, a little over $3 \%$ of the amount injected. One possible explanation for the remaining dye was that it adsorbed to soil, sediments, or bedrock above the cave. It is also possible that the dye passed into a series of fractures unconnected to the cave, or too small for humans to enter, and thus passed to the water table unobserved. Additionally, it is possible that the dye was intercepted by lateral flow prior to entering the Madison formation and was carried away from the sampling area, and possibly even the cave area. Finally, it is possible that the rest of the dye traveled through unexplored cave passages. This last possibility is the least likely. The sample area is located in close proximity to the elevator entrance, and as a result is one of the most thoroughly explored portions of the cave.

More than likely, the fate of the missing rhodamine was a combination of the other three possibilities. Rhodamine
WT is known to adsorb to soils and sediments (Smart, 1977), and as discussed previously, the injection did not occur at a discrete point. Also, the Madison formation is highly fractured in the cave area, as evidenced by the incredibly complex nature of Wind Cave itself. It is not difficult to imagine a myriad of fractures that could have diverted a significant portion of the flow. And finally, intriguing evidence of lateral flow beneath Wind Cave Canyon would come as results from the fluorescein dye trace began to emerge.

\section{The Fluorescein Trace}

Following the injection of the fluorescein on July 29, 1996, a total of 25 sites were repeatedly sampled in the northern portion of the cave. These sites included NFP5, which Davis believed tested positive in her 1986 fluorescein trace, and NM4, which Davis also believed tested positive in her trace and which definitely tested positive for optical brightener following the Lycopodium experiment. Given this past history of the area, it was assumed that a number of sites would receive measurable quantities of dye in this trace.

After 15 months of exhaustive sampling, no sign of the fluorescein was ever discovered in the northern portion of the cave. This came as quite a surprise, since the injection point is very near the Minnelusa/Madison contact. Due to that proximity, it was believed that the dye would travel in a mostly vertical fashion, with little if any lateral movement. While some of it may have traveled vertically via fractures too small for humans to enter, in this case we discovered direct evidence of lateral flow beneath Wind Cave Canyon.

Despite our early assumptions, background sampling was rigorously performed prior to dye injection. Background grab samples and bugs were tested for all dyes that were going to be used, regardless of how unlikely we believed a particular dye might be encountered at a particular site in the future. Between the background sampling performed in June 1996 and routine sampling that occurred during the course of the 1993 dye traces, we knew that fluorescein levels at BI25 and RS11 tended to test a little higher for fluorescein than other cave sites, but always hovered at levels equivalent to $10-14 \mathrm{ppb}$ (Figure 6).

In the days following the dye injection, fluorescein levels at BI25 and RS11 remained at familiar levels. Lulled into complacency by the initial readings and desperate to save time due to the crush of data coming in (we collected nearly 1000 samples during the first month), we briefly stopped measuring for fluorescein at these sites and others that were distant from the injection point. 
This proved to be a major mistake, as we missed the fluorescein's arrival at these sites.

Thus, no fluorescein data for BI25 and RS11 exist between day 19, when it was still within the background range, and day 78, when we resumed fluorescein testing for these sites. By that time, fluorescein levels had nearly doubled at both sites. Levels slowly rose during the course of the fall and winter, and eventually peaked at 40 ppb at BI25 and 38 ppb at RS11 the following spring.

The fluorescein dye curves for these sites were unlike anything we had seen. For more than two years, concentrations fluctuated on what appears to be an annual cycle. Levels were highest during the winter months, as flow rates in the cave slowed, then dropped in the spring as the flow rates accelerated. One possible explanation for this would be that relatively local flow, such as the flow carrying the rhodamine into the cave from the parking lot drain area, dilutes the lateral flow that is presumably carrying the fluorescein down from the north. In other words, the flow we observe at BI25 is a mixture of two separate components, one very local, another with a more distant origin. Such unexpected results cried out for verification. Can we be certain it was indeed fluorescein that was being measured? If so, could it possibly be from an unreported antifreeze leak on the parking lot that exited the drain at the rhodamine injection point?

The answer to the first question arrived in fairly short order. After elution, charcoal bugs retrieved from the site displayed fluorescent green that, especially when illuminated with a bright beam of light, was visible even through the pink cloud produced by the rhodamine at the sites. Later, we discovered that the same could be done with raw samples of water from the site. Joe Meiman at Mammoth Cave provided a more definitive verification via a spectrofluorophotometer. Fluorescein was clearly entering the cave.

The antifreeze spill theory was dismissed after a discussion with an employee from a major antifreeze company, who, after a bit of arm twisting, revealed the rough concentration of fluorescein present in antifreeze. Suffice it to say that it would take at least 1000 liters of raw antifreeze to produce the amount of dye recovered at BI25 over the first two years of sampling. Most of the fluorescein we were encountering simply could not

\section{Fluorescein Concentrations - Upper Minnehaha Falls (BI25)}

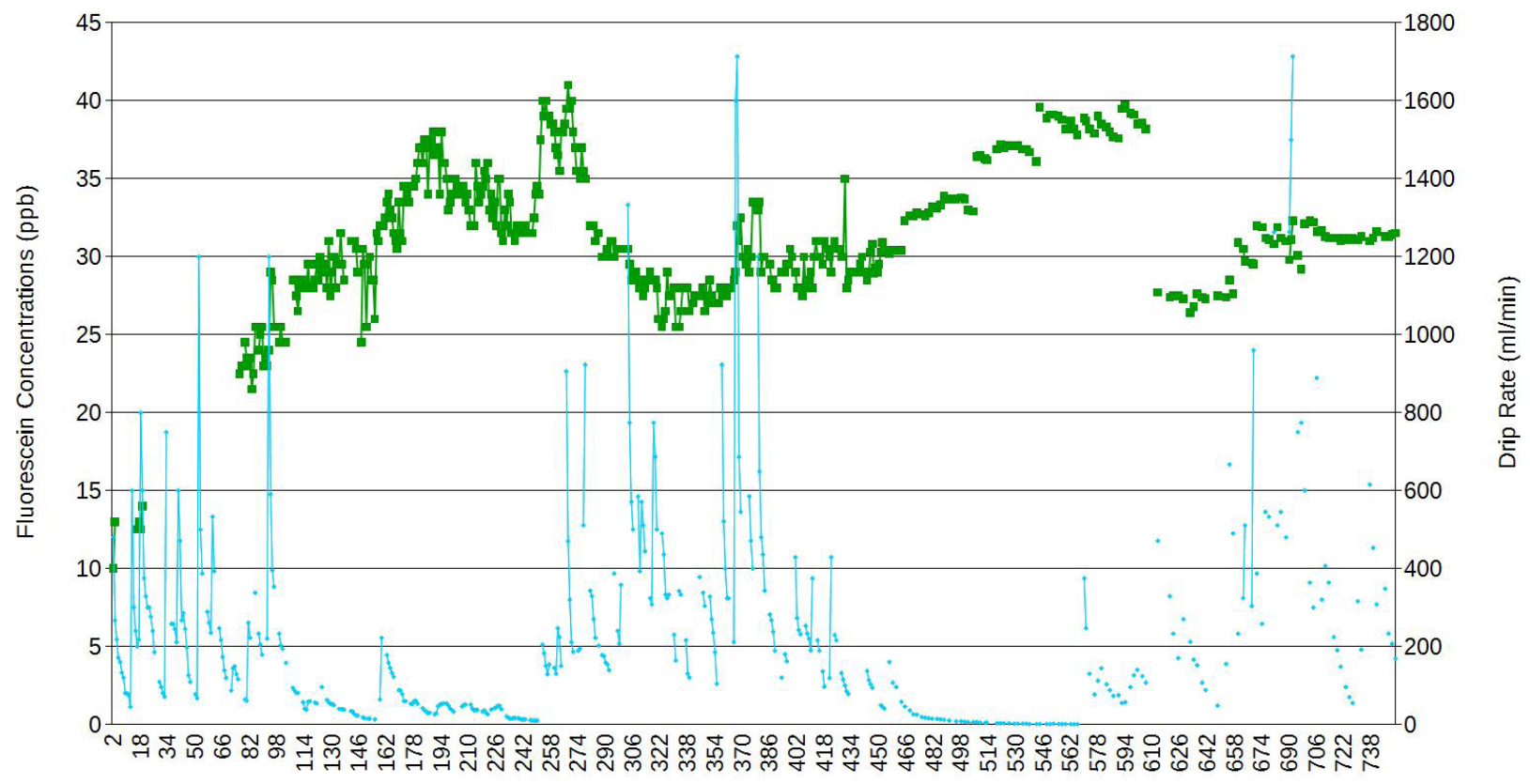

Days Following Injection

Fluorescein $(\mathrm{ppb}) \rightarrow$ Drip Rate $(\mathrm{ml} / \mathrm{min})$

Figure 6. Rising from background levels equivalent to 10-14 ppb, fluorescein settled into a cyclic pattern for the next two years. This fluorescein appears to have travelled 449 meters laterally beneath Wind Cave Canyon to arrive at this location in the cave. 
have come off the parking lot. The only other location that fluorescein had ever been injected above the cave area was a considerable distance down dip from BI25 and RS11, near the southeast corner of the cave.

The fluorescein at these sites simply had to be coming from the picnic ground injection area, and it had not been present at these levels in any of the samples we had tested over the course of the previous three years. In light of all this, and considering the fact that Davis also reported fluorescein at RS11 soon after her 1986 trace, the fluorescein we were detecting is almost certain to have originated with our own 1996 injection in that same area. The lateral distance from the fluorescein injection point to BI25 is 449 meters.

As surprising as it was to verify lateral flow extending up to 449 meters from the injection point, the results closer to the injection point were equally surprising. Davis had reported fluorescein at NFP5 and NM4, and our own serendipitous discovery of optical brightener at NM4 during our Lycopodium experiment seemed to provide independent verification of a hydrologic connection between the picnic ground and NM4. If that connection exists, it did not exhibit itself during the course of this trace, suggesting it is sporadic in nature. Results from other studies suggest this is not unusual for vadose zone traces (Aley, 2012).

An examination of local precipitation data showed that 1986 and 1993 were both much wetter than normal, with an annual total of $58.2 \mathrm{~cm}$ in 1986 and $69.9 \mathrm{~cm}$ in 1993 (Ohms, 2012). Annual precipitation for 1996 was a more average $47.8 \mathrm{~cm}$. Further, precipitation in the two months preceding the 1996 injection was only half of the 30 year average for the area $(7.3 \mathrm{~cm}$, compared to the average $14.5 \mathrm{~cm}$ ). It is possible the system wasn't active enough to move dye to NM4 in 1996.

Not surprisingly, fluorescein also arrived at BI9 at the same time it arrived at BI25, further leading us to believe that most of the water arriving at that site is water that has previously traveled through BI25. The concentrations detected at BI9 consistently lagged behind the concentrations measured at BI25 by 2-3 ppb. The consistency of the data between these two sites, together with a single fluorescein reading from a sample gathered at BI9 on day 29 (ten days into the fluorescein data gap for BI25 and RS11), hints that the fluorescein may have just started to arrive by that date.

On day 29, fluorescein readings were at $14 \mathrm{ppb}$ at BI9, compared to $9 \mathrm{ppb}$ on the day of injection. This was higher than any background sample from the site, and given the consistency of the 2-3 ppb lag behind BI25 readings, suggests that BI 25 would have been reading 16-17 ppb. The increase is small and inconclusive, but it does suggest that it is at least possible that the leading edge of the fluorescein was arriving in the area about a month after injection. If true, the lateral flow beneath Wind Cave Canyon was traveling about 15-16 meters per day.

No other sites that were sampled could conclusively be deemed positive for fluorescein based on grab sample readings, although a small number of sites, including SA1 and UB10, eventually rose slightly above background levels. Charcoal bugs left for months at these sites were visibly fluorescent green after elution, suggesting these sites were positive for fluorescein, albeit very weakly.

\section{Fluorescein Recovery}

Background levels of fluorescein - either due to interference induced by a substance naturally in the water, or due to the presence of actual fluorescein - was present at both BI25 and RS11 in small but measurable levels prior to the July 29, 1996 injection. These background readings were subtracted from readings measured after dye began to arrive in order to arrive at an estimate for the quantity of fluorescein captured at these sites.

When calculated in the same manner as the rhodamine WT totals discussed above, it appears that 3.704 grams of fluorescein dye moved through BI25 during the first 752 days following injection. The total for RS11 during the same time period was 0.071 grams. As with the rhodamine calculations for this site, if we assume that twice as much water is passing through the RS11 area as we were able to capture and measure, then this total could be as high as 0.142 grams. This means that about 3.846 grams of the 2339 grams of fluorescein injected on July $29,1996(0.16 \%$ of the total $)$ can be accounted for during the 752 days following the injection.

A major difference between the rhodamine and fluorescein recovery totals is that while the rhodamine total would not have increased significantly with additional monitoring (since the sites that were still positive when sampling ceased were only weakly positive, and mostly decreasing), the fluorescein levels being measured after 752 days were still quite positive, so fluorescein recovery totals likely would have continued to significantly increase had sampling continued. Figure 7, which documents the daily mass flux for each dye at BI25, illustrates this beautifully. 


\section{Epilogue}

None of the dyes injected in the 1993 and 1996 dye traces ever emerged in measurable quantities at the park well. Grab samples were regularly collected from a spigot in the well house that draws water from the system prior to chlorination, and charcoal bugs were placed in a small piece of PVC pipe that was exposed to water continuously flowing from this spigot. None of the grab samples or bugs ever tested positively for any dye.

This seems to lend validity to Davis' assertion that the rhodamine she found in the park well in the 1980s was the same dye she injected into Beaver Creek two months earlier. During the 1990's park staff also discovered a powerful correlation between mean monthly flow rates in Beaver Creek - as measured by a USGS gaging station - and the rise and fall of the water table in the Lakes portion of the cave. A lag time of roughly two months was observed between a rise in Beaver Creek flow and a corresponding rise in the Lakes - roughly the same amount of time that passed between Davis' rhodamine injection and the appearance of the dye in the well (which is located about the same distance from Beaver Creek as the Lakes area of the cave).

By 1998, sampling in the cave near the 1993 dye injections had grown so infrequent that we could no longer justify keeping the tarps in place that had been used to collect water and measure flow rates. Trips were scheduled to retrieve the tarps, collect final grab samples, and retrieve any bugs that were still present in the cave in those areas.

Four years, 10 months, and one day following the injection of the rhodamine WT in 1993, the collection site at CI17 (Pop Secret) was finally cleaned up. The site is nearly beneath the injection point of the 1993 rhodamine trace, and surprisingly, this sample turned out to be weakly positive for rhodamine - roughly $0.14 \mathrm{ppb}$. Additional grab samples collected 51 and 89 days later both produced readings of $0.36 \mathrm{ppb}$. Although these are the only three samples collected during this time, it appears we inadvertently caught the near-arrival of the dye during the April 1998 sampling.

\section{Daily Dye Recovery - Upper Minnehaha Falls (BI25)}

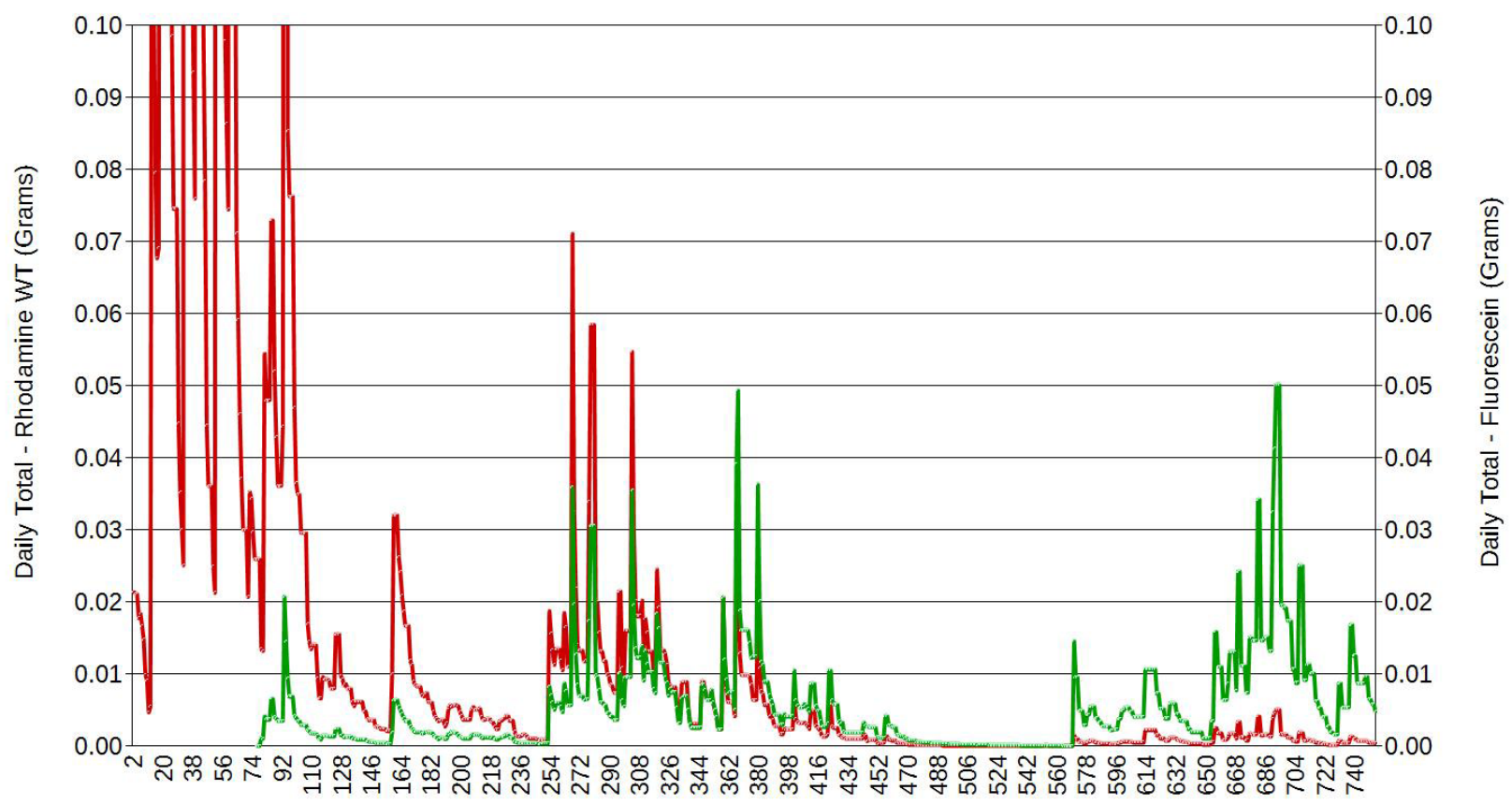

Days Since Injection

Grams of Rhod/Day -2-Grams of Fluor/Day

Figure 7. Quantity of both dyes passing through BI25 on any particular day over time during the first two years of sampling. Graph represents dye recovered, not dye mixture recovered. 
Due to CI17's proximity to the 1993 injection site, and since no dye was recovered in any of the sites between CI17 and the 1996 rhodamine WT injection site, the likeliest explanation is that this represents a weak positive from the 1993 dye traces. Unlike the park's developed area, water apparently takes almost five years to reach the cave here. If a longer lag time between dye injection and initial recovery during a dye trace has ever been measured, this author is not aware of it.

The discovery of dye at CI17 provided us with an additional insight. We had often wondered how long an activated charcoal bug could be left at a drip site in the cave and remain active. The charcoal bug that we retrieved in April 1998 had been in the cave since July 1995. If we are correct in our belief that we discovered the dye relatively soon after its initial appearance in the cave, then a charcoal bug exposed to dripping water at this site could still adsorb dye after being in the cave for nearly three years.

Complete turnover of the park's cave management staff occurred during 1998, and as a result, regular sampling came to an end by late October of that year. Sampling was sporadic during 1999, and continued at some sites on an occasional basis into 2000. Following the collection and analysis of more than 4,400 grab samples and hundreds of bugs throughout the 1990's, this exercise in patience finally came to an end.

\section{Acknowledgments}

It requires discipline to stick to a sampling schedule for years even when positive results fail to materialize. But as we learned, negative results in such experiments can produce valuable information as well, and surprising results can sometimes be attained years after all hope is gone. The author is grateful for the exceedingly dedicated cave management employees - both paid staff and volunteers - who assisted with data collection and analysis, especially Stan Allison, Bob Kobza, Brice Leech, Bonnie-Ann Burnett, and Tonya McDermott.

Marc Ohms continued collecting samples after the author left Wind Cave National Park in October 1998, and has provided very useful information and advice in the intervening years. His patience and diligence in assisting with his predecessor's project helped squeeze the last bits of valuable data out of this long-term experiment.

Finally, NPS hydrologist Joe Meiman provided critical advice and training in study design, and also provided sampling equipment and our first fluorometer. He helped out on numerous occasions when we had trouble inter- preting results, and served as our lead cheerleader when positive data began to pour in. I am deeply grateful for all of his assistance.

\section{References}

Alexander EC, Davis MA, Alexander SC. 1989. Hydrologic study of Jewel Cave/Wind Cave, final report. National Park Service Contract CX-12005-A047.

Aley TJ, Kirkland SL. 2012. Down but not straight down: significance of lateral flow in the vadose zone of karst terrains. Carbonates and Evaporites 27: 193-198.

Nepstad JA. 1997. Surface developments above Wind Cave - studying the impacts. In: Stitt RR, editor. Proceedings of the 1997 Karst and Cave Management Symposium; Bellingham, Washington. p. 137-140.

Ohms MJ. 2012. Water resources of Wind Cave National Park - 2012 update. National Park Service report.

Palmer AN, Palmer M. 2008. Field guide to the paleokarst of the southern Black Hills. In: Saskowski ID, Feazel CT, Mylroie JE, Palmer AN, Palmer MV, editors. Karst Waters Institute Conference Karst From Recent to Reservoirs. Karst Waters Institute Special Publication 14.

Smart PL, Laidlaw IMS. 1977. An evaluation of some fluorescent dyes for water tracing. Water Resources Research 13 (1): 15-33.

Strobel ML, Jarrell GJ, Sawyer JF, Schleicher JR, Fahrenbach MD. 1999. Distribution of hydrogeologic units in the Black Hills, South Dakota. U.S. Geological Survey Hydrologic Investigations Atlas HA-743. 
